\title{
Therapeutic Monitoring of Gastroenteropancreatic Neuroendocrine Tumors: The Challenges Ahead
}

\author{
Anders Sundin ${ }^{\mathrm{a}} \quad$ Andrea Rockall $^{\mathrm{b}}$ \\ a Department of Radiology, Karolinska University Hospital, Molecular Medicine and Surgery, Karolinska Institute, \\ Stockholm, Sweden; ${ }^{\text {b}}$ Department of Radiology, Bart's Cancer Centre, King George V Wing, St. Bartholomew's \\ Hospital, West Smithfield, London, UK
}

\section{Key Words \\ Neuroendocrine tumors - Imaging • Response criteria • \\ RECIST - PERCIST - Computed tomography · Positron emission tomography $\cdot{ }^{68} \mathrm{Ga} \cdot{ }^{18} \mathrm{~F}$-labelled L-DOPA $\cdot$ \\ ${ }^{11} \mathrm{C}-5$-hydroxytryptophan}

\begin{abstract}
Background: Gastroenteropancreatic neuroendocrine tumors (NETs), a heterogeneous family of tumors arising in a variety of anatomic sites, are generally well differentiated and often metastatic at diagnosis. Morphologic and functional imaging modalities have vastly improved the understanding and diagnosis of NETs. However, use of conventional imaging techniques and response criteria to assess treatment response is often complicated by the clinical course and cytostatic nature of oncologic treatments for NETs. Materials and Methods: The means of therapeutic monitoring discussed in this review were based on a PubMed search of the medical literature and on the clinical expertise of the authors. Results: Morphology-based criteria for assessing tumor response in general oncology are presented, along with their limitations for assessing response in gastrointestinal and pancreatic NETs. Functional imaging and preliminary response criteria incorporating functional imaging are pre-
\end{abstract}

sented as possible solutions to monitoring treatment response in NETs. Conclusions: Morphology-based criteria to assess tumor response have limitations for NETs, which are often slow growing and frequently demonstrate low response rates when based on conventional radiological criteria. Furthermore, many NET treatments do not induce cytotoxic effects despite demonstrated clinical benefit. Novel imaging techniques are available which have the potential to measure changes in tumor physiology and metabolism. These include ${ }^{68} \mathrm{Ga}$-labelled somatostatin analogs for PET/ CT-based monitoring of NET, molecular imaging with PET tracers that are not based on somatostatin receptor targeting, and functional MRI. These techniques should be explored as options for monitoring treatment in patients with NET.

Copyright $\odot 2012$ S. Karger AG, Basel

\section{Introduction}

Neuroendocrine tumors (NETs) are a heterogeneous family of tumors that are increasing in incidence [1]. The clinical presentation and clinical course of NETs are dependent on anatomical location, tumor stage, and functional status. Functional tumors are characterized by

\section{KARGER \\ Fax +41613061234 \\ E-Mail karger@karger.ch}

www.karger.com (c) $2012 \mathrm{~S}$. Karger AG, Basel

0028-3835/12/0964-0261\$38.00/0

Accessible online at:

www.karger.com/nen
Anders Sundin

Department of Radiology

Karolinska University Hospital

SE-171 76 Stockholm (Sweden)

Tel. +4670 799 9621, E-Mail anders.sundin@ki.se 
their ability to secrete bioactive amines such as 5-hydroxytryptamine (serotonin) that are associated with carcinoid symptoms (i.e. diarrhea, flushing, abdominal pain). By contrast, nonfunctioning tumors do not generate clinical symptoms and signs.

The wide range of clinical course of NETs results in the very diverse demands for therapy and imaging to monitor response. Surgery remains the primary modality for cure in patients with limited disease [2]. When this is not possible, medical therapy with somatostatin analogs are the mainstay for control of hormone-related symptoms associated with NETs as well as suppression of disease progression. In addition to symptom control, treatment with long-acting somatostatin analogues has demonstrated antitumor activity, prolonging time to disease progression in patients with naïve metastatic small bowel NETs [3]. More recently, the targeted therapies, including the oral mTOR inhibitor everolimus and the tyrosine kinases inhibitor sunitinib have been shown to improve progression-free survival in patients with progressive malignant disease $[4,5]$. Peptide receptor radionucleotide therapy (PRRT) using ${ }^{177} \mathrm{Lu}$ - or ${ }^{90} \mathrm{Y}$-labelled octreotide has also shown promising results in patients with disseminated disease [6].

Regardless of the treatment chosen, imaging plays a pivotal role in follow-up surveillance and assessment of response in patients with NETs [7-10]. However, the complex clinical course of NETs and cytostatic nature of many NET treatments pose specific challenges for the assessment of response. In this article, we review practical approaches and limitations of current imaging techniques as well as future perspectives on tumor response evaluation in NET. The information presented was based on a PubMed search of the literature and on the clinical expertise of the authors.

\section{Morphological Imaging Techniques}

Morphological or structural imaging technologies available for assessment of NETs include CT, MRI, and ultrasonography. Additionally, somatostatin receptor scintigraphy (SRS; OctreoScan ${ }^{\circledR}$; Mallinckrodt Inc., Maryland Heights, Mo., USA) is often used for initial staging of the disease and to evaluate the somatostatin receptor status and thereby the patients' eligibility for somatostatin analog therapy [9-11]. For some patients with metaiodobenzylguanidine (MIBG)-avid tumors, MIBG scintigraphy may be helpful, both for assessment of extent of disease and to identify those patients in whom
MIBG therapy is appropriate. These imaging techniques are used to assess the morphologic features (CT and MRI) and receptor status of NETs, to identify changes in the target lesions over time, and to detect new tumors through use of serial imaging. Each of these modalities has advantages and disadvantages dependent upon tumor location, comorbidities (e.g. extent of abdominal and retroperitoneal fat, and renal insufficiency), type of treatment, and length of follow-up.

Multidetector CT (MDCT) is the current standard morphologic imaging modality for NET $[9,10]$. MRI is also advantageous for NET imaging, $[7,8]$ and is often used as a problem-solving tool as well as for patients with a history of adverse effects to iodine contrast material or for those with renal insufficiency $[7,9]$. Ultrasound and MDCT may be complementary. Many lesions are equally well depicted by both techniques, but in some patients the lesions are visualized more clearly, or solely, by only one of these modalities. However, ultrasound may be more useful in thin patients, whereas MDCT is advantageous in large and obese patients and patients with a large tumor burden. Additionally, certain therapies (e.g. $\alpha$-interferon and chemotherapy) can alter imaging conditions, thus require change in modality. For example, fatty infiltration changes the imaging conditions for three-phase intravenous contrast-enhanced MDCT of the liver such that liver metastases previously visualized in one phase may instead be best visualized in another. Contrast-enhanced ultrasound is capable of detecting $<5$-mm liver metastases and may characterize equivocal lesions seen on MDCT.

One advantage of MDCT is that it is always performed in the transaxial plane, thus facilitating comparison of baseline and follow-up examinations. However, the accumulated radiation dose associated with MDCT must be considered as follow-up in NETs and is often prolonged. Comparison of serial ultrasound images is often complicated by variability in imaging planes used during imaging. Standardization of ultrasound examination protocols and the increasing use of 'video clips' stored in the digital image archive have facilitated between-examination comparisons.

Given the advantages and disadvantages of MDCT and ultrasound and the possible changes in imaging conditions during follow-up, some centers advocate alternating MDCT and ultrasound. Alternating modalities reduces the accumulated radiation dose for patients undergoing MDCT. Particularly in younger patients, dose reduction may be achieved by using MRI for initial and follow-up examinations. 
Table 1. WHO, SWOG, RECIST, and RECIST 1.1 criteria for measuring tumor response

\begin{tabular}{|c|c|c|c|c|}
\hline & WHO [12] & SWOG [13] & RECIST [14] & RECIST 1.1 [15] \\
\hline $\begin{array}{l}\text { Definition } \\
\text { of target } \\
\text { lesions }\end{array}$ & $\begin{array}{l}\text { all bidimensionally measurable } \\
\text { lesions }\end{array}$ & $\begin{array}{l}\text { all bidimensionally measurable } \\
\text { lesions }\end{array}$ & $\begin{array}{l}\text { all unidimensionally } \\
\text { measurable lesions up to } 5 \text { per } \\
\text { organ and } 10 \text { total; chosen } \\
\text { lesions should be those with } \\
\text { longest diameters, } \\
\text { representative of all involved } \\
\text { organs, and most suitable for } \\
\text { accurate repeated } \\
\text { measurement }\end{array}$ & $\begin{array}{l}\text { all unidimensionally measurable } \\
\text { lesions up to } 2 \text { per organ and } 5 \\
\text { total; chosen lesions should be } \\
\text { those with longest diameters, } \\
\text { representative of all involved } \\
\text { organs, and most suitable for } \\
\text { accurate repeated measurement }\end{array}$ \\
\hline
\end{tabular}

\begin{tabular}{|c|c|c|c|c|}
\hline \multicolumn{5}{|c|}{ Response categories } \\
\hline CR & $\begin{array}{l}\text { disappearance of all known } \\
\text { disease, determined by } 2 \\
\text { observations } \geq 4 \text { weeks apart }\end{array}$ & $\begin{array}{l}\text { disappearance of all } \\
\text { measurable and evaluable } \\
\text { disease; no evidence of } \\
\text { nonevaluable disease, } \\
\text { including normalization of } \\
\text { markers and other abnormal } \\
\text { laboratory values for } \geq 6 \text { weeks }\end{array}$ & $\begin{array}{l}\text { disappearance of all target } \\
\text { lesions }\end{array}$ & $\begin{array}{l}\text { disappearance of all target lesions; } \\
\text { if present, all pathologic lymph } \\
\text { nodes must have reduction in } \\
\text { short axis to }<10 \mathrm{~mm}\end{array}$ \\
\hline $\mathrm{PR}$ & $\begin{array}{l}\geq 50 \% \text { decrease in sum of product } \\
\text { of longest diameter and greatest } \\
\text { perpendicular diameter of all } \\
\text { measured lesions, determined by } 2 \\
\text { observations } \geq 4 \text { weeks apart, in the } \\
\text { absence of new lesions or } \\
\text { progression of individual lesions }\end{array}$ & $\begin{array}{l}\geq 50 \% \text { decrease in sum of } \\
\text { products of all lesions for } \\
\geq 3-6 \text { weeks in the absence of } \\
\text { new lesions or progression of } \\
\text { evaluable lesions }\end{array}$ & $\begin{array}{l}\geq 30 \% \text { decrease in sum of } \\
\text { longest diameter of target } \\
\text { lesions, taking baseline sum } \\
\text { longest diameter as reference, } \\
\text { in the absence of new lesions } \\
\text { or disease progression }\end{array}$ & $\begin{array}{l}\geq 30 \% \text { decrease in sum of } \\
\text { diameters of target lesions } \\
\text { (longest diameter for nonnodal } \\
\text { and short axis for nodal lesions), } \\
\text { taking baseline sum diameter } \\
\text { (longest diameter for nonnodal, } \\
\text { short axis for nodal) as reference }\end{array}$ \\
\hline PD & $\begin{array}{l}\geq 25 \% \text { increase in product of } \\
\text { longest diameter and greatest } \\
\text { perpendicular diameter of } \geq 1 \\
\text { measured lesion or appearance of } \\
\text { new lesions }\end{array}$ & $\begin{array}{l}>50 \% \text { or }>10 \mathrm{~cm}^{2} \text { (whichever } \\
\text { is smaller) in sum of products } \\
\text { of all measurable lesions, } \\
\text { taking the smallest sum } \\
\text { observed as reference, or } \\
\text { appearance of a new lesion or } \\
\text { clear worsening of any } \\
\text { evaluable disease }\end{array}$ & $\begin{array}{l}\geq 20 \% \text { increase in sum of } \\
\text { longest diameter of target } \\
\text { lesions, taking smallest sum } \\
\text { longest diameter recorded } \\
\text { since treatment started as } \\
\text { reference, or appearance of } \geq 1 \\
\text { new lesions }\end{array}$ & $\begin{array}{l}\geq 20 \% \text { relative increase and } \\
\geq 5 \text {-mm absolute increase in sum } \\
\text { of diameter of target lesions } \\
\text { (longest diameter for nonnodal } \\
\text { and short axis for nodal lesions), } \\
\text { taking smallest sum diameter } \\
\text { (longest diameter for nonnodal } \\
\text { and short axis for nodal lesions) } \\
\text { recorded since treatment started } \\
\text { as reference or appearance of } \geq 1 \\
\text { new lesions }\end{array}$ \\
\hline $\mathrm{SD}$ & $\begin{array}{l}\text { neither sufficient shrinkage to } \\
\text { qualify for PR nor sufficient } \\
\text { increase to qualify for PD }\end{array}$ & $\begin{array}{l}\text { neither sufficient shrinkage to } \\
\text { qualify for PR nor sufficient } \\
\text { increase to qualify for PD }\end{array}$ & $\begin{array}{l}\text { neither sufficient shrinkage to } \\
\text { qualify for PR nor sufficient } \\
\text { increase to qualify for PD, } \\
\text { taking smallest sum longest } \\
\text { diameter recorded since } \\
\text { treatment started as reference }\end{array}$ & $\begin{array}{l}\text { neither sufficient shrinkage to } \\
\text { qualify for PR nor sufficient } \\
\text { increase to qualify for PD, taking } \\
\text { smallest sum diameter (longest } \\
\text { diameter for nonnodal and short } \\
\text { axis for nodal lesions) recorded } \\
\text { since treatment started as } \\
\text { reference }\end{array}$ \\
\hline
\end{tabular}

$\mathrm{CR}=$ Complete response; $\mathrm{PD}=$ progressive disease; $\mathrm{PR}=$ partial response; $\mathrm{SD}=$ stable disease; $\mathrm{SWOG}=\mathrm{Southwestern} \mathrm{Oncology}$ Group; $\mathrm{WHO}=$ World Health Organization.

\section{Evaluation of Morphologic Treatment Response}

\section{Overview of Response Criteria}

Criteria for the measurement of tumor response have evolved substantially over the last three decades. The first widely adopted system for response assessment was published by the WHO in 1979 [12]. The WHO recommended the use of standardized approaches to disease assessment to facilitate cross-center comparisons and, for the first time, proposed categorization of treatment response (table 1). Tumors were measured manually or on chest X-ray in two dimensions, with the cross-sectional area determined by multiplying the longest diameter by the greatest perpendicular diameter. The products of all measured tumors were then summed and compared with baseline. Unfortunately, interpretation 
and application of the WHO criteria were inconsistent between centers.

The advent of new imaging technologies and classes of anticancer agents led to a series of modification to the WHO criteria [13, 14]. The Response Evaluation Criteria In Solid Tumors (RECIST) was proposed by an international working group collaboration of the European Organisation for Research and Treatment of Cancer (EORTC), the United States National Cancer Institute (NCI), and the National Cancer Institute of Canada Clinical Trials Group that was tasked with reviewing and revising the WHO criteria to improve standardization and incorporate the use of CT and MRI (table 1) [14]. RECIST recommends the selection of measurable tumor lesions, or 'those with the longest diameter'. The choice of measurable lesions should also be governed by 'their suitability for accurate repeated measurements', be solid, not cystic, and be 'representative of all involved organs'. A maximum of 5 lesions per organ, up to a maximum of 10 overall, should be measured. Comparison of the sums of the longest diameters of all measurable lesions before and after treatment is used to evaluate the category of response (table 1). Notably, and as opposed to the WHO criteria, RECIST states that although complete response, partial response, and stable disease should be related to the tumor load at baseline, determination of progressive disease should be related to the imaging date at which the sum of the target lesions is the smallest [14].

In 2009, the RECIST criteria were updated to address the importance of disease progression as a primary endpoint and the pivotal role of target lesions in gauging tumor response. The RECIST v1.1 criteria provide recommendations for lymph node assessment, identification of new lesions, and the role of nontarget lesions in the declaration of partial response or stable disease [15]. Pathological lymph nodes with a short axis of $>15 \mathrm{~mm}$ are considered as target lesions and the short axis measurement should be included in the sum of lesion diameters in the calculation of tumor load. Nodes between 10 and $15 \mathrm{~mm}$ are considered nonmeasurable disease. Other notable changes include a reduction in the number of target lesions required for assessment of response to a maximum of 2 per organ and a maximum of 5 lesions in total as well as the inclusion of $\left[{ }^{18} \mathrm{~F}\right]$ fluorodeoxyglucose positron emission tomography (FDG-PET) to identify new lesions $[15,16]$.

The results of trials using the different response criteria cannot be compared due to key differences when moving from the WHO criteria to RECIST. For example, the requirement for an increase in tumor volume in order to result in progressive disease is considerably higher with RECIST than with the WHO criteria. Given that the tumor represents a sphere, and that the increase in tumor volume also takes place in a spherical fashion, the formula to calculate the volume of a sphere $\left(4 / 3 \pi r^{3}\right)$ can be used. Thus, an increase in the tumor diameter (d) by $20 \%$ (RECIST) corresponds to a $40 \%$ larger volume, whereas a $25 \%$ increase of the products of the diameters $\left(\mathrm{d}^{2}\right)$ (WHO) leads to a $73 \%$ increase of the tumor volume. The outcome of a trial evaluating time to progression is therefore likely to produce better results if response is determined by RECIST rather than the WHO criteria. Moreover, progressive disease according to $\mathrm{WHO}$ is based on comparison with the base-line examination, whereas in RECIST the comparison should be made with the examination with the smallest tumor load, the nadir.

\section{Limitations of RECIST Response Rate}

The pitfalls of conventional morphologic imaging in evaluating disease after treatment are well established. Inherent difficulties include identifying and monitoring small volume disease, defining and reproducibly measuring individual large volume liver metastases because they form conglomerate masses (fig. 1a, b), accurately visualizing vascular metastases given differences in the timing of contrast administration (fig. 1c, d), and time lag before tumor shrinkage occurs after the start of chemotherapy and radiotherapy [17]. Additionally, a discrepancy between patient outcomes and decrease in tumor size has been well documented in patients with gastrointestinal stromal tumors treated with imatinib $[18,19]$. Similarly, the limitations of RECIST in predicting survival have been noted in patients with advanced hepatocellular carcinoma treated with sorafenib [20]. In the SHARP trial, only $2 \%$ of patients in the treated group demonstrated a partial response by RECIST despite improvement in overall survival [20]. These findings suggest that lack of tumor shrinkage may not predict poor outcome in patients treated with targeted therapies because tumors may respond to targeted therapy by undergoing necrosis or cystic changes without decreasing, and possibly even increasing, in size. Residual masses or fibroses that do not contain viable tumor can cause further uncertainty [20].

Assessment of response by RECIST can be particularly problematic in patients with highly differentiated, slow-growing NETs receiving somatostatin analogs to relieve hormonal symptoms. Treatment with long-acting somatostatin analogues has been shown to prolong progression-free survival compared with placebo in patients with treatment-naïve small bowel NETs [3], indicating an 

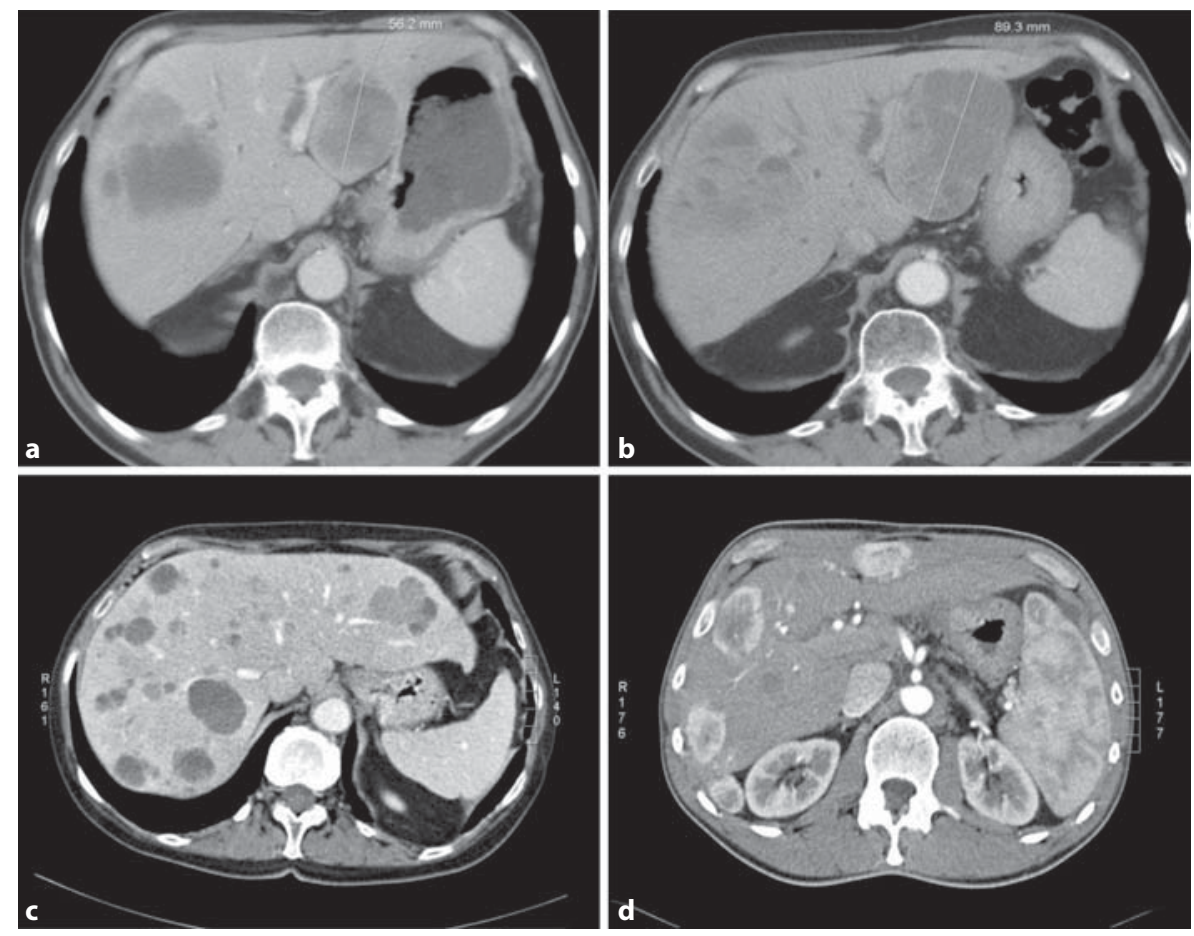

Fig. 1. Examples of metastases that are difficult to monitor using conventional imaging techniques. a Initial imaging of individual large volume liver metastases on July 7, 2007. The measured mass in the left lobe can be reproducibly measured. However, the lesion in the right lobe could be measured as three separate lesions or as one lesion, leading to poor reproducibility. b Follow-up imaging on May 8, 2008. The left lobe lesion can be reproducibly measured. However, the configuration of the right lobe conglomerate mass did not lend itself to a reproducible measurement of the original three adjacent lesions. c CT in the venous contrast enhancement phase showing poorly vascularized liver metastases as low attenuating (dark) rounded and partly lobulated lesions in the contrastenhanced high attenuation (light gray) normal liver parenchyma. d CT in the early arterial (portal-venous inflow) contrast enhancement phase showing well-vascularized liver metastases as high attenuating (white) rounded-oval lesions in the not yet enhanced low attenuating (dark gray) normal liver parenchyma. antiproliferative action. Similarly, newer targeted therapies including everolimus have demonstrated improved progression-free survival in NET patients; however, the effect on the tumor volume is often minimal, with 'stabilization' of the tumor size being the best outcome for most patients $[4,5]$. Thus, RECIST criteria may be less well suited for assessment of treatment response in slowgrowing NETs than in general oncology. Clearly, there are limitations with morphological evaluation of NETs and the current evaluation criteria.

\section{Functional Imaging: Overcoming the Problems of Morphologic Imaging?}

Functional imaging provides information on tumor physiology and therefore may have great potential for measuring treatment response in patients in whom tu- mor shrinkage is not anticipated. Response to targeted therapies that demonstrate cytostatic versus cytocidal effects may be associated predominantly with a decrease in metabolism, even in the absence of a major reduction in tumor size. Consequently, changes in the physiologic or metabolic characteristics of the tissue may be more predictive of outcome than the tumor size criteria used by RECIST. Physiologic changes can be detected much earlier than changes in size, allowing for individualized rather than generic treatment [21]. Because prolonged ineffective treatment is costly to both patients and health care systems, it would be preferable to have an early assessment that offers a 'window of opportunity' to optimize or alter the treatment plan in any patient not achieving a satisfactory response with current treatment.

Characterization of tumors based on their specific functional imaging characteristics and expected response pattern may also be advantageous to predicting 
outcomes. Tumor heterogeneity is seen not just between patients, but also between primary and secondary deposits and even within the same tumor mass [22]. The significance of intratumoral heterogeneity has become important because it may highlight groups of treatment-resistant cells for which it is now possible to direct targeted therapy [23] or biopsy.

\section{Therapy Monitoring by Functional Imaging}

Several functional imaging techniques including dynamic contrast-enhanced (DCE) MRI, diffusion weighted MRI (DW-MRI), PET, and single-photon emission CT (SPECT) have demonstrated promising ability to provide quantitative information regarding the physiologic and molecular characteristics of tumors unavailable with conventional morphologic imaging techniques. Many factors, including microvessel density, capillary permeability, tumor oxygenation, and interstitial fluid pressure, are involved in the delivery of treatments to the tumor, and are known to affect the response and outcome [24]. Thus, the ability to measure several of the tumor's vascular parameters has enormous potential in better understanding the nature of the tumor. A detailed review of these techniques has been published $[25,26]$.

\section{Molecular Imaging Techniques}

Many PET tracers may be used for various aspects of tumor imaging by PET/CT. FDG, reflecting glucose metabolism, is by far the most widely used and $\left[{ }^{18} \mathrm{~F}\right]$ fluorothymidine [27] is increasingly being explored to quantify tumor proliferation. For gastrointestinal stromal tumors, response to imatinib was associated with a marked decrease of FDG uptake as well as tumor attenuation on contrast-enhanced CT [19]. Based on the latter findings, Choi et al. [19] published a proposal for new CT tumor response criteria that take into account the combination of changes in tumor attenuation on contrast-enhanced $\mathrm{CT}$ and lesion size that became the first accepted adaption to morphologic criteria by the incorporation of observed physiological changes within the tumor (table 2) $[18,19]$. For general oncology applications, the EORTC has published guidelines on how to use FDG-PET for monitoring cancer treatment (table 2) [28]. The document describes the image evaluation procedure whereby two regions of interest - a small region of interest encompassing the region of high FDG uptake representing a viable tumor and a large region of interest encompassing the tumor circumference to quantify the overall tumor uptake - should be drawn on a slice in which there is a high tumor FDG uptake. The maximum long axis of FDG tumor uptake is also documented. The NCI PET group subsequently published the results of a consensus meeting on FDG-PET for cancer therapy monitoring that focused on details regarding patient preparation, image acquisition, reconstruction and analysis, quality assurance, and reproducibility [29].

An interesting extension of the EORTC and NCI recommendations that partially incorporates the morphologic RECIST is Positron Emission Tomography Response Criteria in Solid Tumors (PERCIST) 1.0 (table 2) [30]. In PERCIST, response to therapy is assessed as a continuous variable and expressed as a percentage change in standardized uptake value (SUV) corrected for lean body mass (SUL) peak between the pre- and posttreatment scans. Briefly, a complete metabolic response is defined as the visual disappearance of all metabolically active tumors, whereas a partial response is classified as more than a $30 \%$ and a 0.8 -unit decline in SUL peak between the most intense lesion before treatment and the most intense lesion after treatment. More than a $30 \%$ and 0.8 unit increase in SUL peak or new lesions is considered progressive disease. Of note, the target lesion with the highest uptake is measured, which may not be the same lesion that was measured at the baseline examination. Recently, guidelines for tumor PET imaging published by the European Association for Nuclear Medicine have been adapted to include the PERCIST criteria [31].

\section{Functional Imaging in NETs}

\section{Somatostatin Receptor Scintigraphy and \\ ${ }^{68} \mathrm{Ga}$-DOTATOC}

Because of the issues involved in evaluating responses to targeted therapy in patients with NETs using classic morphologic criteria, it is important to explore functional and molecular imaging techniques. Somatostatin receptor imaging by SRS remains the standard molecular imaging technique for NET visualization [17] and is used in the initial imaging workup to stage the disease and to evaluate the eligibility for somatostatin analog treatment. SRS is also used for monitoring NET treatment and is valuable as a complement in patients with biochemical or clinical progressive disease for the detection of new lesions that have escaped depiction by morphologic imaging.

In recent years, SRS has been superseded by PET/ CT performed with ${ }^{68} \mathrm{Ga}$-labelled octreotide. Of several 
Table 2. Tumor response criteria that incorporate functional imaging

\begin{tabular}{|c|c|c|c|}
\hline $\begin{array}{l}\text { Response } \\
\text { category }\end{array}$ & Choi, et al. ${ }^{1}[19]$ & EORTC [28] & PERCIST [30] \\
\hline CMR & $\begin{array}{l}\text { disappearance of all lesions and no new } \\
\text { lesions }\end{array}$ & $\begin{array}{l}\text { complete resolution of }\left[{ }^{18} \mathrm{~F}\right]-\mathrm{FDG} \text { uptake } \\
\text { within the tumor volume so that it is } \\
\text { indistinguishable from surrounding normal } \\
\text { tissue }\end{array}$ & $\begin{array}{l}\text { complete resolution of }{ }^{18} \mathrm{~F}-\mathrm{FDG} \text { uptake within } \\
\text { measurable target lesion so that the liver activity } \\
\text { was less than the mean and indistinguishable } \\
\text { from surrounding background blood-pool levels } \\
\text { plus disappearance of all other lesions to } \\
\text { background blood pool levels and appearance of } \\
\text { no new }{ }^{18} \mathrm{~F}-\mathrm{FDG} \text {-avid lesions }\end{array}$ \\
\hline PMR & $\begin{array}{l}\geq 10 \% \text { decrease in size per RECIST or } \\
\geq 15 \% \text { decrease in HU on CT plus no } \\
\text { new lesions and no obvious progression } \\
\text { of nonmeasurable disease }\end{array}$ & $\begin{array}{l}\text { minimum } 15-25 \% \text { reduction in tumor } \\
{ }^{18} \mathrm{~F}-\mathrm{FDG} \text { SUV after } 1 \text { chemotherapy cycle } \\
\text { and }>25 \% \text { reduction after } \geq 1 \text { treatment } \\
\text { cycle; reduction in extent of tumor } \\
{\left[{ }^{18} \mathrm{~F}\right]-\text { FDG uptake not required }}\end{array}$ & $\begin{array}{l}\geq 30 \% \text { relative and } \geq 0.8 \text { SUL unit absolute } \\
\text { reduction in target measurable tumor }{ }^{18} \mathrm{~F}-\mathrm{FDG} \\
\text { SUL peak and no increase }>30 \% \text { in SUL or size } \\
\text { (per RECIST) of target or nontarget lesions or } \\
\text { appearance of new lesions; reduction in extent of } \\
\text { tumor }{ }^{18} \mathrm{~F} \text {-FDG uptake not required }\end{array}$ \\
\hline SMD & $\begin{array}{l}\text { does not meet criteria for CMR, PMR, } \\
\text { or PMD and no symptomatic } \\
\text { deterioration attributed to tumor } \\
\text { progression }\end{array}$ & $\begin{array}{l}<25 \% \text { increase or }<15 \% \text { decrease in tumor } \\
{ }^{18} \mathrm{~F} \text {-FDG SUV and no visible increase in } \\
\text { extent of }{ }^{18} \mathrm{~F}-\mathrm{FDG} \text { tumor uptake ( }>20 \% \text { in } \\
\text { the longest dimension) }\end{array}$ & not CMR, PMR, or PMD \\
\hline
\end{tabular}

$\mathrm{CMR}=$ Complete metabolic response; $\mathrm{HU}=$ Hounsfield unit $\mathrm{PMD}=$ progressive metabolic disease; $\mathrm{PMR}=$ progressive metabolic response; $\mathrm{SMD}=$ stable metabolic disease.

${ }^{1}$ Using contrast-enhanced CT, attenuation measurement is taken at the level of maximum transverse diameter and encompasses the entire tumor.

preparations of radiolabelled octreotide, ${ }^{68} \mathrm{Ga}$-DOTATOC is the most widely used. ${ }^{68} \mathrm{Ga}$-DOTATOC PET/CT provides better spatial resolution and higher tumor-tonormal tissue ratios than SRS and SPECT (fig. 2), and its sensitivity to detect NET exceeds that of SRS and SPECT [32]. Conveniently, ${ }^{68} \mathrm{Ga}$-DOTATOC PET/CT requires no patient preparation with laxatives, and the examination can be performed as a one-session outpatient procedure approximately $1 \mathrm{~h}$ after tracer injection. Unfortunately, the results of therapy monitoring with ${ }^{68} \mathrm{Ga}$-DOTATOC PET/CT have been unconvincing. In one report, no advantage was found for ${ }^{68} \mathrm{Ga}$-DOTATOC PET/CT over conventional radiologic imaging in assessing response to PRRT except that the development of new metastases was detected earlier in a few patients by ${ }^{68} \mathrm{Ga}$-DOTATOC PET/CT [33]. Tumor maximum SUV ( $\left.\mathrm{SUV}_{\max }\right)$ at baseline did not predict outcome and no correlation was noted between change in tumor $\mathrm{SUV}_{\max }$ and outcome. In another study, tumor $\mathrm{SUV}_{\max }$ measurements were similarly inconclusive, though patients with decreased tu- mor-to-spleen ratios after the first PRRT cycle had longer progression-free survival according to RECIST than those with stable or increased ratios; decreased tumor-tospleen ratio correlated with clinical improvement [34]. These findings suggest that decrease in the somatostatin receptor expression/density assessed by ${ }^{68} \mathrm{Ga}$-DOTATOC $\mathrm{PET} / \mathrm{CT}$ is not predictive of PRRT response. Moreover, the possibility of tumor dedifferentiation with loss of receptors is an obvious obstacle and must be taken into account. This view is supported in a recent guideline paper on tumor imaging using ${ }^{68} \mathrm{Ga}$-DOTA-labelled peptides [35].

\section{FDG-PET/CT}

As it is in general oncology, FDG-PET/CT is useful for the staging of NETs with high proliferative capacity and clinically aggressive behavior (e.g. poorly differentiated endocrine carcinomas). In a recent study, the sensitivity of FDG-PET (92\%) for depicting NETs with a proliferation index $>15 \%$ exceeded that of SRS (69\%) and MIBG 


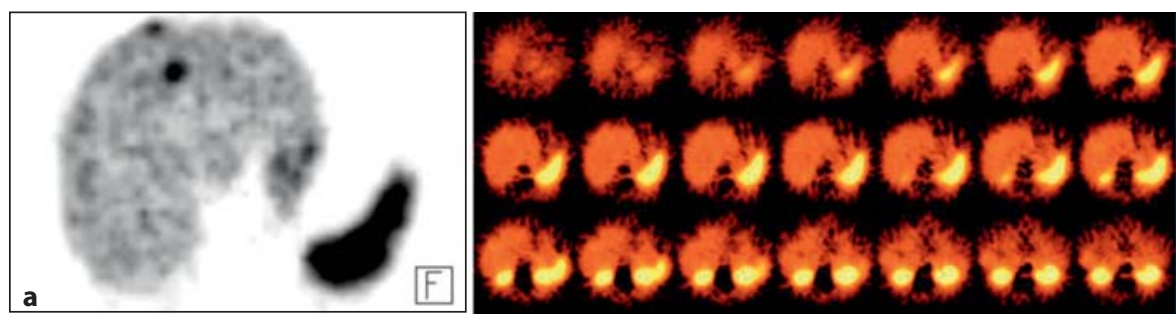

Fig. 2. Comparison of ${ }^{68} \mathrm{Ga}-\mathrm{DOT} A T O C$ PET and SRS (OctreoScan). a Transaxial PET image showing two metastases in the ventral aspect of the liver (left panel). The normal high ${ }^{68} \mathrm{Ga}$ DOTATOC uptake in the spleen is apparent. SPECT of the liver in the same patient shows normal findings (right panel). $\mathbf{b}^{68} \mathrm{Ga}$ DOTATOC PET (maximum intensity projection) showing multiple liver metastases and two lymph node metastases in the upper-right aspect of the abdomen (left panel). Posterior and anterior acquisitions from planar imaging in the same patient are normal (right panel).

scintigraphy (46\%) [36]. Other researchers showed that more information can be gained by combining ${ }^{68} \mathrm{Ga}$ DOTATATE and FDG-PET, because of a significant correlation between histologic tumor grade and predominant tumor uptake of ${ }^{68} \mathrm{Ga}$-DOTATATE or FDG [37]. Interestingly, FDG-PET has a stronger prognostic value than traditional markers such as $\mathrm{Ki} 67, \mathrm{CgA}$, and the presence of liver metastases [38]. Others have shown that FDG-PET positivity at the time of diagnosis in patients with metastatic NETs correlates with reduced progression-free and overall survival [39].

\section{Future Prospects for NET Imaging}

Based on the limitations of SRS and ${ }^{68} \mathrm{Ga}$-DOTATOC PET/CT for monitoring therapy in patients with NETs, who typically have non-FDG-avid, well-differentiated tumors, a molecular imaging tool that reflects metabolic changes in a tumor rather than one that depicts receptor density may be a more convincing approach to monitoring therapy. Because of the capacity of NET cells for amine precursor uptake and decarboxylation (the APUD system) [40], precursors such as 5-hydroxy-L-tryptophan (5-HTP) and L-dihydroxyphenylalanine (L-DOPA) may be taken up by NET cells and converted to serotonin and dopamine, respectively, which are stored in secretory granulae within the cytoplasm. The APUD pathway has been used to produce PET tracers such as ${ }^{11} \mathrm{C}$-labelled L-

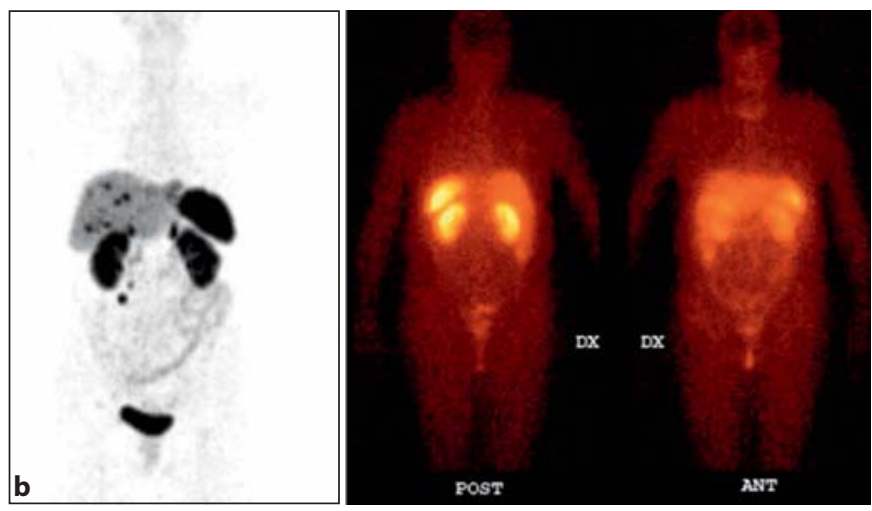

DOPA $\left({ }^{11} \mathrm{C}\right.$-L-DOPA) and, more commonly, ${ }^{18} \mathrm{~F}$-labelled L-DOPA (F-DOPA) and ${ }^{11} \mathrm{C}$-labelled 5-HTP $\left({ }^{11} \mathrm{C}-5\right.$-HTP) to visualize NETs [40-45].

In a recent study of 61 patients, F-DOPA-PET/CT showed $91 \%$ sensitivity and $96 \%$ specificity for NET detection and resulted in a change of therapy in more than one quarter of the patients [44]. In a larger study of 82 patients, the accuracy of F-DOPA-PET/CT for initial NET localization and staging, follow-up, and diagnosis of recurrent disease was confirmed [45]. In comparative studies, however, the use of ${ }^{68} \mathrm{Ga}$-labelled octreotide rather than F-DOPA has been shown to be more advantageous for NET visualization [46-48].

Although published studies measuring labeled L-DOPA or 5-HTP uptake before and during treatment for monitoring therapy in NET are lacking, interesting results have been noted from small studies in the setting of therapeutic monitoring. In 10 patients with NET who underwent dynamic ${ }^{11} \mathrm{C}-5$-HTP-PET scanning at different intervals during treatment, there was a correlation between changes in the ${ }^{11} \mathrm{C}-5$-HTP transport rate constant and urinary 5-hydroxyindoleacetic acid levels [41]. However, these results would need to be corroborated in a larger cohort of patients. In 2 patients with pancreatic NETs (gastrinoma and glucagonoma) who underwent ${ }^{11} \mathrm{C}$-DOPA-PET before and during somatostatin analog treatment, tumor accumulation of ${ }^{11} \mathrm{C}$-DOPA by contrast 
increased despite clinically relevant reductions in $\mathrm{CgA}$, gastrin, and glucagon [49]. This increase may reflect reduced exocytosis secondary to somatostatin analog treatment and, hence, increased storage of the tracer within the cells.

Currently, the feasibility of 5-HTP-PET and L-DOPAPET for therapeutic monitoring in NETs is limited by the few centers that have the capability to perform the procedure. The use of ${ }^{11} \mathrm{C}-5-\mathrm{HTP}-\mathrm{PET}$ is restricted to two centers in Europe and one in the United States, and the use of ${ }^{11} \mathrm{C}$-L-DOPA is also limited. ${ }^{18} \mathrm{~F}-\mathrm{DOPA}$ is, however, more readily available and is used in a number of institutions. With the rapid increase in the number of centers capable of performing PET, the use of ${ }^{18} \mathrm{~F}$-DOPA-PET for monitoring therapy in NETs may be feasible if data supporting its usefulness are published and the anecdotal result of increased tumor uptake of ${ }^{11} \mathrm{C}$-DOPA during somatostatin analog therapy [49] is not confirmed.

Other functional imaging modalities that may play a future role in monitoring treatment response in NET are DCE CT/MRI/ultrasound and DW-MRI. DCE is a technique that evaluates changes in attenuation (CT), signal intensity (MRI), or echogenicity (ultrasound) after the injection of intravenous contrast media. DCE imaging permits the investigation of tumor vasculature by evaluating the transit of an intravenous contrast medium from vessels to the tissue with leakage from capillaries into the interstitial space and eventual rediffusion into the venous system. Changes in tumor vascularity after treatment may be assessed by analyzing changes in contrast enhancement within the tumor over time [50], with changes expected relatively soon after a response to treatment. Although DCE-CT quantitative measures of enhancement are relatively straightforward and reproducible, patients are exposed to a relatively high radiation dose [51]. Conversely, DCE-MRI is a nonradioactive technique and may be used to describe qualitative changes in gadolinium uptake over time. Notably, preliminary work on evaluating neuroendocrine liver metastases with DCE-MRI has demonstrated potential for categorization of metastases by their vascular characteristics [52]. Negative aspects of DCE-MRI include the requirement for rapid image acquisition to obtain quantitative results and the lack of a linear relationship between gadolinium concentration in the tissue and signal intensity. Further, DCE-MRI shows an intrapatient variability of up to $20 \%$ on the same MRI system [53], which may limit its ability to serve as a means of monitoring response to therapy.

DW-MRI, a functional imaging technique that depicts the microscopic Brownian motion of water molecules, al- lows for noninvasive characterization of biological tissues based on their water diffusion characteristics. The rationale for using DW-MRI to monitor treatment response lies in its potential to detect measurable increases in water diffusivity upon apoptosis, which may reflect treatment response [54]. Changes in water diffusivity may occur much earlier than changes in tumor size and thereby may provide an early response indicator [55]. DW-MRI is attractive as a potentially quantifiable means of assessing response because it is noninvasive, reproducible, does not require exogenous contrast agents or use ionizing radiation, is easily incorporated into routine patient evaluations, and can be obtained relatively rapidly. Although promising, the use of DW-MRI for monitoring treatment response in NET has not been widely evaluated.

\section{Conclusion}

Accurate monitoring of treatment response is a critical component of patient management and the investigation of new therapies. RECIST criteria are the mainstay of evaluation of response in clinical trials, and in poorly differentiated gastroenteropancreatic NETs, these are a valid tool. A number of limitations exist with the use of conventional morphologic and functional imaging criteria for the assessment of response in well-differentiated gastroenteropancreatic NETs. In contrast with common cancers, which are of generally high proliferative activity and have a measurable size response to chemotherapy and radiotherapy, NETs tend to grow slowly, have a low proliferative rate, and (depending on the treatment), patient outcome may not correlate with significant changes in tumor size. RECIST criteria may also be difficult to apply in patients with NETs with hepatic metastases due to the changes in the appearance of metastases following contrast administration as well as coalescence of lesions and the subsequent inability to delineate individual tumors that may be accurately and reproducibly measured. Given the prognostic importance of liver involvement in NETs, we suggest that new or modified evaluation criteria should report the liver metastatic fraction as a potential measure of response. Further, stable disease per RECIST in a patient with previously progressive disease may represent a treatment response to targeted therapies and further research is needed in order to test these hypotheses.

The potential role of molecular imaging techniques in monitoring treatment response in patients with NETs requires further evaluation. In the future, molecular imag- 
ing with radiolabelled L-DOPA and 5-HTP-PET/CT and functional imaging modalities such as DCE-MRI/CT and DW-MRI have the potential to demonstrate early physiological changes that may predict responders and nonresponders early in the course of treatment. However, there are several issues to overcome with these modalities, including high cost, lack of facilities able to perform the imaging, and need for cross-site standardization.

The role of ${ }^{68} \mathrm{Ga}$-labelled somatostatin analogs for $\mathrm{PET} / \mathrm{CT}$ monitoring of NET therapies remains an impor- tant avenue for further research. Molecular imaging with PET tracers reflective of metabolic pathways and functional imaging should also be explored as options for monitoring treatment in patients with NETs.

\section{Acknowledgments}

We acknowledge Kathy Covino, PhD, of ApotheCom for editorial assistance in preparing the manuscript for submission.

\section{References}

1 Yao JC, Hassan M, Phan A, et al: One hundred years after 'carcinoid': epidemiology of and prognostic factors for neuroendocrine tumors in 35,825 cases in the United States. J Clin Oncol 2008;26:3063-3072.

$\checkmark 2$ Turaga KK, Kvols LK: Recent progress in the understanding, diagnosis, and treatment of gastroenteropancreatic neuroendocrine tumors. CA Cancer J Clin 2011;61:113-132.

$\checkmark 3$ Rinke A, Muller HH, Schade-Brittinger C, et al: Placebo-controlled, double-blind, prospective, randomized study on the effect of octreotide LAR in the control of tumor growth in patients with metastatic neuroendocrine midgut tumors: a report from the PROMID Study Group. J Clin Oncol 2009; 27:4656-4663.

\4 Raymond E, Dahan L, Raoul JL, Bang YJ, Borbath I, Lombard-Bohas C, Valle J, Metrakos P, Smith D, Vinik A, Chen JS, Hörsch D, Hammel P, Wiedenmann B, Van Cutsem E, Patyna S, Lu DR, Blanckmeister C, Chao R, Ruszniewski P: Sunitinib malate for the treatment of pancreatic neuroendocrine tumors. N Engl J Med 2011;364:501-513, erratum: N Engl J Med 2011;364:1082.

$\checkmark 5$ Yao JC, Shah MH, Ito T, Bohas CL, Wolin EM, Van Cutsem E, Hobday TJ, Okusaka T, Capdevila J, de Vries EG, Tomassetti P, Pavel ME, Hoosen S, Haas T, Lincy J, Lebwohl D, Öberg K, RAD001 in Advanced Neuroendocrine Tumors, Third Trial (RADIANT-3) Study Group: Everolimus for advanced pancreatic neuroendocrine tumors. N Engl J Med 2011;364:514-523.

6 6 Kwekkeboom DJ, de Herder WW, Krenning EP: Somatostatin receptor-targeted radionuclide therapy in patients with gastroenteropancreatic neuroendocrine tumors. Endocrinol Metab Clin North Am 2011;40:173185.

7 Rockall AG, Reznek RH: Imaging of neuroendocrine tumors (CT/MR/US). Best Pract Res Clin Endocrinol Metab 2007;21:43-68.
Rockall AG, Planche K, Power N, Nowosinska E, Monson JP, Grossman AB, et al: Detection of neuroendocrine liver metastases with MnDPDP-enhanced MRI. Neuroendocrinology 2009;89:288-295.

-9 Sundin A, Vullierme MP, Kaltsas G, Plockinger U: ENETS Consensus Guidelines for the Standards of Care in Neuroendocrine Tumors: radiological examinations. Neuroendocrinology 2009;90:167-183.

10 Vinik AI, Woltering EA, Warner RR, Caplin M, O’Dorisio TM, Wiseman GA, Coppola D, Go VL: North American Neuroendocrine Tumor Society (NANETS): NANETS consensus guidelines for the diagnosis of neuroendocrine tumor. Pancreas 2010;39:713734.

11 Sundin A, Garske U, Orlefors H: Nuclear imaging of neuroendocrine tumors. Best Pract Res Clin Endocrinol Metab 2007;21:69-85.

12 World Health Organization: WHO Handbook for Reporting Results of Cancer treatment. WHO Offset Publication No. 48 (pamphlet). Geneva, World Health Organization, 1979.

$>13$ Green S, Weiss GR: Southwest Oncology Group standard response criteria, endpoint definitions and toxicity criteria. Invest New Drugs 1992;10:239-253.

14 Therasse P, Arbuck SG, Eisenhauer EA, et al: New guidelines to evaluate the response to treatment in solid tumors. J Natl Cancer Inst 2000;92:205-216.

15 Eisenhauer EA, Therasse P, Bogaerts J, et al: New response evaluation criteria in solid tumours: revised RECIST guideline (version 1.1). Eur J Cancer 2009;45:228-247.

16 Schwartz LH, Bogaerts J, Ford R, et al: Evaluation of lymph nodes with RECIST 1.1. Eur J Cancer 2009;45:261-267.

17 Padhani AR, Ollivier L: The RECIST (Response Evaluation Criteria in Solid $\mathrm{Tu}$ mours) criteria: implications for diagnostic radiologists. Br J Radiol 2001;74:983-986.
18 Hong X, Choi H, Loyer EM, Benjamin RS, Trent JC, Charnsangavej C: Gastrointestinal stromal tumor: role of $\mathrm{CT}$ in diagnosis and in response evaluation and surveillance after treatment with imatinib. Radiographics 2006;26:481-495.

19 Choi H, Charnsangavej C, Faria SC, et al: Correlation of computed tomography and positron emission tomography in patients with metastatic gastrointestinal stromal tumor treated at a single institution with imatinib mesylate: proposal of new computed tomography response criteria. J Clin Oncol 2007;25:1753-1759.

20 Llovet JM, Ricci S, Mazzaferro V, et al: Sorafenib in advanced hepatocellular carcinoma. N Engl J Med 2008;359:378-390.

21 Cheson BD, Pfistner B, Juweid ME, et al: Revised response criteria for malignant lymphoma. J Clin Oncol 2007;25:579-586.

22 Miller TR, Pinkus E, Dehdashti F, Grigsby PW: Improved prognostic value of ${ }^{18} \mathrm{~F}-\mathrm{FDG}$ PET using a simple visual analysis of tumor characteristics in patients with cervical cancer. J Nucl Med 2003;44:192-197.

23 Bentzen SM: Theragnostic imaging for radiation oncology: dose-painting by numbers. Lancet Oncol 2005;6:112-117.

24 Milosevic M, Fyles A, Hedley D, Pintilie M, Levin W, Manchul L, et al: Interstitial fluid pressure predicts survival in patients with cervix cancer independent of clinical prognostic factors and tumor oxygen measurements. Cancer Res 2001;61:6400-6405.

25 Torigian DA, Alavi A: The evolving role of structural and functional imaging in assessment of age-related changes in the body. Semin Nucl Med 2007;37:64-68.

26 Higgins LJ, Pomper MG: The evolution of imaging in cancer: current state and future challenges. Semin Oncol 2011;38:3-15.

27 Frings V, de Langen AJ, Smit EF, et al: Repeatability of metabolically active volume measurements with ${ }^{18} \mathrm{~F}-\mathrm{FDG}$ and ${ }^{18} \mathrm{~F}$-FLT PET in non-small cell lung cancer. J Nucl Med 2010;51:1870-1877. 
28 Young H, Baum R, Cremerius U, et al: Measurement of clinical and subclinical tumour response using $\left[{ }^{18} \mathrm{~F}\right]$-fluorodeoxyglucose and positron emission tomography: review and 1999 EORTC recommendations. European Organization for Research and Treatment of Cancer (EORTC) PET Study Group. Eur J Cancer 1999;35:1773-1782.

-29 Shankar LK, Hoffman JM, Bacharach S, et al: Consensus recommendations for the use of ${ }^{18} \mathrm{~F}-\mathrm{FDG}$ PET as an indicator of therapeutic response in patients in National Cancer Institute Trials. J Nucl Med 2006;47:10591066.

$>30$ Wahl RL, Jacene H, Kasamon Y, Lodge MA: From RECIST to PERCIST: evolving considerations for PET response criteria in solid tumors. J Nucl Med 2009;50 Suppl 1:122S$150 \mathrm{~S}$.

-31 Boellaard R, O’Doherty MJ, Weber WA, et al: FDG PET and PET/CT: EANM procedure guidelines for tumour PET imaging: version 1.0. Eur J Nucl Med Mol Imaging 2010;37: 181-200.

32 Gabriel M, Decristoforo C, Kendler D, et al: ${ }^{68} \mathrm{Ga}$-DOTA-Tyr3-octreotide PET in neuroendocrine tumors: comparison with somatostatin receptor scintigraphy and CT. J Nucl Med 2007;48:508-518.

-33 Gabriel M, Oberauer A, Dobrozemsky G, et al: ${ }^{68} \mathrm{Ga}$-DOTA-Tyr3-octreotide PET for assessing response to somatostatin-receptormediated radionuclide therapy. J Nucl Med 2009;50:1427-1434.

$\checkmark 34$ Haug AR, Auernhammer CJ, Wangler B, et al: ${ }^{68} \mathrm{Ga}$-DOTATATE PET/CT for the early prediction of response to somatostatin receptor-mediated radionuclide therapy in patients with well-differentiated neuroendocrine tumors. J Nucl Biol Med 2010;51:13491356.

35 Virgolini I, Ambrosini V, Bomanji JB, et al: Procedure guidelines for PET/CT tumour imaging with ${ }^{68} \mathrm{Ga}$-DOTA-conjugated peptides: ${ }^{68} \mathrm{Ga}-\mathrm{DOTA}-\mathrm{TOC},{ }^{68} \mathrm{Ga}$-DOTA-NOC, ${ }^{68} \mathrm{Ga}$-DOTA-TATE. Eur J Nucl Med Mol Imaging 2010;37:2004-2010.

-36 Binderup T, Knigge U, Loft A, et al: Functional imaging of neuroendocrine tumors: a head-to-head comparison of somatostatin receptor scintigraphy, ${ }^{123} \mathrm{I}-\mathrm{MIBG}$ scintigraphy, and ${ }^{18}$ F-FDG PET. J Nucl Med 2010;51: 704-712.
Kayani I, Bomanji JB, Groves A, et al: Functional imaging of neuroendocrine tumors with combined PET/CT using ${ }^{68} \mathrm{Ga}$-DOTATATE (DOTA-DPhe1,Tyr3-octreotate) and ${ }^{18}$ F-FDG. Cancer 2008;112:2447-2455.

38 Binderup T, Knigge U, Loft A, Federspiel B, Kjaer A: ${ }^{18} \mathrm{~F}$-fluorodeoxyglucose positron emission tomography predicts survival of patients with neuroendocrine tumors. Clin Cancer Res 2010;16:978-985.

39 Garin E, Le JF, Devillers A, et al: Predictive value of ${ }^{18} \mathrm{~F}$-FDG PET and somatostatin receptor scintigraphy in patients with metastatic endocrine tumors. J Nucl Med 2009; 50:858-864.

40 Pearse AG: The APUD concept and hormone production. Clin Endocrinol Metab 1980;9: 211-222.

41 Orlefors H, Sundin A, Ahlstrom H, et al: Positron emission tomography with 5-hydroxytryprophan in neuroendocrine tumors. J Clin Oncol 1998;16:2534-2541.

42 Orlefors H, Sundin A, Lu L, et al: Carbidopa pretreatment improves image interpretation and visualisation of carcinoid tumours with ${ }^{11} \mathrm{C}-5$-hydroxytryptophan positron emission tomography. Eur J Nucl Med Mol Imaging 2006;33:60-65.

43 Koopmans KP, Neels OC, Kema IP, et al: Improved staging of patients with carcinoid and islet cell tumors with ${ }^{18} \mathrm{~F}$-dihydroxyphenyl-alanine and ${ }^{11} \mathrm{C}-5$-hydroxy-tryptophan positron emission tomography. J Clin Oncol 2008;26:1489-1495.

44 Schiesser M, Veit-Haibach P, Muller MK, et al: Value of combined $6-\left[{ }^{18} \mathrm{~F}\right]$ fluorodihydroxyphenylalanine PET/CT for imaging of neuroendocrine tumours. Br J Surg 2010;97: 691-697.

45 Kauhanen S, Seppanen M, Ovaska J, et al: The clinical value of $\left[{ }^{18} \mathrm{~F}\right]$ fluoro-dihydroxyphenylalanine positron emission tomography in primary diagnosis, staging, and restaging of neuroendocrine tumors. Endocr Relat Cancer 2009;16:255-265.
46 Haug A, Auernhammer CJ, Wangler B, et al: Intraindividual comparison of ${ }^{68} \mathrm{Ga}$-DOTATATE and ${ }^{18} \mathrm{~F}$-DOPA PET in patients with well-differentiated metastatic neuroendocrine tumours. Eur J Nucl Med Mol Imaging 2009;36:765-770.

47 Putzer D, Gabriel M, Kendler D, et al: Comparison of (68)Ga-DOTA-Tyr(3)-octreotide and (18)F-fluoro-L-dihydroxyphenylalanine positron emission tomography in neuroendocrine tumor patients. Q J Nucl Med Mol Imaging 2010;54:68-75.

48 Ambrosini V, Tomassetti P, Castellucci P, et al: Comparison between ${ }^{68} \mathrm{Ga}-\mathrm{DOTA}-\mathrm{NOC}$ and ${ }^{18} \mathrm{~F}$-DOPA PET for the detection of gastro-entero-pancreatic and lung neuro-endocrine tumours. Eur J Nucl Med Mol Imaging 2008;35:1431-1438.

49 Bergström M, Eriksson B, Oberg K, et al: In vivo demonstration of enzyme activity in endocrine pancreatic tumors: decarboxylation of carbon-11-DOPA to carbon-11-dopamine. J Nucl Med 1996;37:32-37.

50 Yopp AC, Schwartz LH, Kemeny N, et al: Antiangiogenic Therapy for Primary Liver Cancer: Correlation of Changes in Dynamic Contrast-Enhanced Magnetic Resonance Imaging with Tissue Hypoxia Markers and Clinical Response. Ann Surg Oncol 2011;18: 2192-2199.

51 Goh V, Dattani M, Farwell J, et al: Radiation dose from volumetric helical perfusion CT of the thorax, abdomen or pelvis. Eur Radiol 2011;21:974-981.

52 Koh TS, Thng CH, Hartono S, et al: Dynamic contrast-enhanced MRI of neuroendocrine hepatic metastases: a feasibility study using a dual-input two-compartment model. Magn Reson Imaging 2011;65:250-260.

53 Ng CS, Raunig DL, Jackson EF et al: Reproducibility of perfusion parameters in dynamic contrast-enhanced MRI of lung and liver tumors: effect on estimates of patient sample size in clinical trials and on individual patient responses. AJR Am J Roentgenol 2010;194:W134-W140.

54 Chenevert TL, Meyer CR, Moffat BA, et al: Diffusion MRI: a new strategy for assessment of cancer therapeutic efficacy. Mol Immunol 2002;1:336-343.

55 Pickles MD, Gibbs P, Lowry M, Turnbull LW: Diffusion changes precede size reduction in neoadjuvant treatment of breast cancer. Magn Reson Imaging 2006;24:843-847. 